\title{
DETERMINATION OF SEDIMENT PHOSPHATE SORPTION CHARACTERISTICS IN SHALLOW MOGAN LAKE, TURKEY
}

\author{
TOPÇU, A. ${ }^{1^{*}}-$ Ulusoy, U. $^{2}-$ PULATSÜ, S. ${ }^{1}$ \\ ${ }^{1}$ Department of Fisheries and Aquaculture Engineering, Agricultural Faculty, Ankara \\ University, Ankara, Turkey \\ (e-mail:spulatsu@agri.ankara.edu.tr) \\ ${ }^{2}$ Department of Chemistry, Faculty of Science, Cumhuriyet University, Sivas, Turkey \\ (e-mail: ulusoy@cumhuriyet.edu.tr) \\ *Corresponding author \\ e-mail: atopcu@.ankara.edu.tr; phone:+90-312-596-1648, fax: +90-312-318-5298 \\ (Received 20 $0^{\text {th }}$ Jun 2018; accepted 22 ${ }^{\text {nd }}$ Aug 2018)
}

\begin{abstract}
This study was conducted on sediment and overlying water samples from Mogan Lake, an important recreational area, in April, July and October 2015 and January 2016. The noteworthy data for this study were presented as follows: a) Sediment adsorption/desorption characteristics dependent on phosphate concentration, temperature and time were determined using models, and the relevant parameters were derived. b) Sediment equilibrium phosphate concentrations $\left(\mathrm{EPC}_{0}\right)$ and the critical dissolved phosphorus in the overlyingwater were estimated. Presentation of the research data is as follows: a) Phosphorous adsorption in the sediment samples was theoretically between $421 \mathrm{mgP} \mathrm{kg}^{-1}$ and $1,001 \mathrm{mgP} \mathrm{kg}^{-1}$, and phosphorus sorption efficiency was estimated at $0.21-1.92 \mathrm{~L} \mathrm{mg}^{-1}$. Based on the Langmuir Model, the mean maximum adsorption capacity obtained for the July samples was significantly higher than that obtained for October $(\mathrm{p}<0.05)$. Moreover, regarding the very low degree of sediment phosphorus desorption $(<1 \%)$, it can be concluded that sediment does not behave as a desorbant material for phosphorus. b) Considering the $\mathrm{EPC}_{0}$ values $\left(5.5 \times 10^{-3}\right.$ and $\left.46.6 \times 10^{-3} \mathrm{mg} \mathrm{L}^{-1}\right)$, when the overlying water SRP concentrations fall below $0.008 \mathrm{mg} \mathrm{L}^{-1}$ in October and $0.046 \mathrm{mg} \mathrm{L}^{-1}$ in July, there will be a risk of phosphorus flux from the sediment to the lake water. Considering the overlying water SRP values reported for Lake Mogan, monitoring them in the months of October and July will prove to be decisive in predicting the internal phosphorus load of the lake.
\end{abstract}

Keywords: adsorption, desorption, Freundlich model, Langmuir model, phosphorus, sediment

\section{Introduction}

Phosphate sorption (adsorbtion/desorbtion) between the sediment and the sediment porewater is one of the mechanisms controlling phosphate exchange between the sediment and the overlying water in aquatic ecosystems. In determining the sediment's role as either a trap or a source of phosphorus, sediment phosphate adsorption is recognized as one of the most important components of long-term phosphate retention mechanisms especially in shallow lakes (Wang and Li, 2010; Zhang et al., 2012). Longterm estimates of sediment phosphate adsorption are important in determining phosphate pollution and suitable restoration techniques in lakes. The measurement of the most recent phosphate concentration in lake water is not restricted to the lake's phosphate intake and the measures taken to reduce its phosphate level; it can also be determined using the phosphate sorption rate. Kinetic models of sediment phosphate adsorption are defined by Langmuir isotherm (a rational basis) and Freundlich isotherm (an empirical equation) these are generally used in determining the rate of the chemical reaction and the effective factors following the calculation of the equilibrium phosphate concentration (Huang et al., 2011). The above models are often excellent at describing 
adsorption, which are simply numerical relationships used to curve-fit data. Langmuir and Freundlich equations, widely and well used to explain the $\mathrm{K}$ adsorption, took into account the quantity, intensity and capacity factors which are important for estimating the sediment nutrient amounts (Wang et al., 2017).

The equilibrium phosphate concentration $\left(\mathrm{EPC}_{0}\right)$ is the state of aquatic systems in which adsorption and desorption values between the sediment and the overlying water are equal. It is an important parameter used for determining internal phosphate loading potential following a reduction in external phosphate loading or for measuring the level of phosphorus release and/or retention (Palmer-Felgate et al., 2011; Zhijian et al., 2012). If the equilibrium phosphate concentration is greater than the SRP value of the overlying water, phosphate release from the sediment into the overlying water occurs (Wang and Li, 2010; Wang et al., 2012; Jin et al., 2013; Tang et al., 2014).

Lake Mogan is an important recreational area for metropolitan Ankara, Turkey. It is under environmentally protected status as the 'Golbasi Specially Protected Area' since the major source of phosphorus in the area is wastewater containing detergents and fertilizers applied in the surrounding agricultural areas. Lake Mogan is an important recreational area due to its proximity to the city of Ankara, and studies have been conducted on the interaction between eutrophication and sediment in the lake (Pulatsü et al., 2008; Topçu and Pulatsü, 2008; Pulatsü and Topçu, 2009).

This study, being the pioneer one regarding the determination of sediment phosphate sorption characteristics, was conducted in Lake Mogan in April, July, and October 2015 and January 2016 with the aims of: a) deriving parameters for the use of kinetic and thermodynamic models for adsorption/desorption features of sediment phosphates in terms of concentration, temperature and time, and b) estimating the critical total dissolved phosphate concentration for the overlying water by calculating the sediment's equilibrium phosphate concentration $\left(\mathrm{EPC}_{0}\right)$.

\section{Materials and methods}

\section{Study area}

Lake Mogan is located $20 \mathrm{~km}$ south of Ankara on the Ankara-Konya road. It is an alluvial lake fed in large part by rain and also by more than five large and small streams (Boşgelmez et al., 2005). Detailed locations of the sampling stations in Mogan Lake are shown in Figure 1. Because the eastern littoral area's lakebed is covered with stones, the two stations were placed near the lake's western shore, where the lakebed is more suitable for collecting sediment samples. The area surrounding the sampling stations is covered with rooted aquatic macrophytes and is under the effects of intense negative development and pollution from anthropogenic sources.

\section{Sediment sampling and analyses}

All sediment samples were collected from the surface sediment $(0-20 \mathrm{~cm})$ in April, July, October 2015 and January 2016 with Van Veen Grab. Prior to mixing and splitting the sediment samples, they were taken to the laboratory in sealed plastic bags, which were put in iceboxes. After that these samples were air-dried, homogenized by grinding, and finally passed through a $0.5 \mathrm{~mm}$ sieve. The overlying water was grained by siphoning from the water located $10 \mathrm{~cm}$ above the sediment sampling locations. The mean depth of the sampling stations vary between 2.20 and $2.80 \mathrm{~m}$. The supernatants of 
overlying water were filtered through Whatman GF/C filters and then analyzed for SRP as ascorbic acid method according to standard analytical procedures (APHA, 2005). Two samples were obtained from each station and dublicate sub-samples were used for every sample in all analyses.

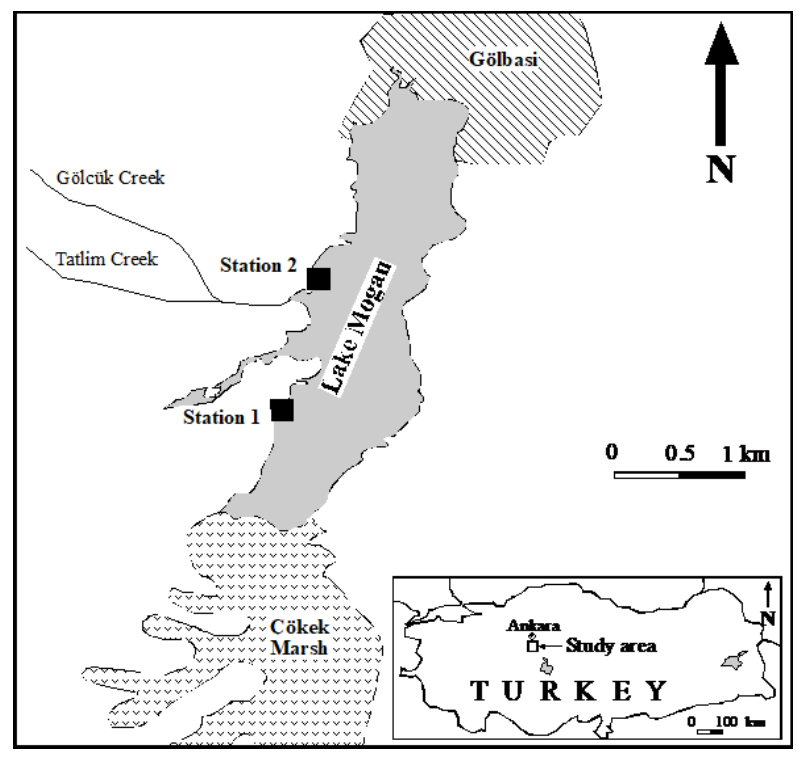

Figure1. Study site and sampling stations (m: Station 1: 3946’07” N 3247’03” E; Station 2: 39॰45'33” N 32॰47’05” E) in Mogan Lake

\section{Adsorption procedures}

Phosphorous adsorption studies were performed for various temperatures $(277,289$, 295 and $300 \mathrm{~K})$. The change of adsorption by phosphorous concentration was investigated for the range of $0.1-10 \mathrm{mg} \mathrm{L}^{-1}$ by considering previous investigations related to the seasonal change of phosphorous release in Mogan Lake by Pulatsu et al. (2008) at 277, 289, 295 and 300 K. 0.2 g fractions of sediment samples exemplified for July and October were added in screw-cap centrifuge tubes containing $20 \mathrm{~mL}$ of 0.1 $10 \mathrm{mg} \mathrm{L}^{-1}$ phosphorous equivalent $\mathrm{KH}_{2} \mathrm{PO}_{4}\left(\mathrm{Ca} \approx 0.4-40 \mathrm{mg} \mathrm{L}^{-1}\right)$ solutions at studied temperatures. Two drops of $0.1 \%$ chloroform to inhibit bacterial activity. The samples were let to equilibrate for $24 \mathrm{~h}$ in temperature controlled water bath with gentle agitations. The solution and solid phases were separated by centrifugation at $4000 \mathrm{rpm}$ for $15 \mathrm{~min}$. Solutions were filtered and the phosphorous contents were determined by the APHA procedures (2005). This prescription was also applied for investigations enquiring the effect of time (kinetics) at 277 and $300 \mathrm{~K}$ and temperature (thermodynamics) at 289, 295 and $300 \mathrm{~K}$ on phosphorous adsorption at constant phosphorous concentration $\left(2 \mathrm{mg} \mathrm{L}^{-1}\right)$. The solid and solution interaction was $24 \mathrm{~h}$ for the temperature effect whilst that was variable from $10 \mathrm{~min}$ to $36 \mathrm{~h}$ for the kinetics.

\section{Calculation of phosphate desorption}

The experimental processes of desorption measurement (change of desorption with concentration, thermodynamic, and kinetic), the 'desorbant (sediment)-phosphorus equilibrium solution' balance in the system, the 'phosphorus' concentrations were measured with spectrophotometric methods. 


\section{Data evaluation}

The adsorbed amounts ' $\mathrm{Q}$ ' ( $\left.\mathrm{mg} \mathrm{kg}^{-1}\right)$ were calculated by Equation 1 where ' $\mathrm{C}_{0}$ and $\mathrm{C}_{\mathrm{e}}$ ' were phosphorous concentrations $\left(\mathrm{mg} \mathrm{L}^{-1}\right)$, ' $\mathrm{V}$ ' was solution volume $(\mathrm{L})$, and ' $\mathrm{m}$ ' was the mass of adsorbent $(\mathrm{kg})$.

$$
Q=\frac{\left(C_{0}-C_{e}\right) x V}{m}
$$

The concentration dependence of adsorption was evaluated with reference to the compatibility of experimental data $\left(\mathrm{Q}\right.$ vs. $\mathrm{C}_{\mathrm{e}}$ ) to Langmuir, Freundlich and Sips models (Eqs. 2-4) in which $\mathrm{X}_{\mathrm{L}}\left(\mathrm{mg} \mathrm{kg}^{-1}\right)$ and $\mathrm{K}_{\mathrm{L}}\left(\mathrm{L} \mathrm{mg}^{-1}\right)$ were monolayer adsorption capacity and a constant energetically related to the adsorbate affinity to adsorbent. According to Langmuir model the active adsorptive centers were homogeneously distributed over the surface; the amount of adsorbate filling of these centers completely was $\mathrm{X}_{\mathrm{L}}$.

$$
Q=\frac{X_{L} K_{L} C_{e}}{1+K_{L} C_{e}}
$$

Freundlich model was description of adsorption exponentially related to the surface heterogeneity ' $0<\beta<1$ ' where ' $a$ ' was Freunlich capacity constant associated with adsorption intensity.

$$
Q=a C_{e}^{\beta}
$$

' $\mathrm{K}_{\mathrm{s}}$ ' and ' $\mathrm{a}_{\mathrm{s}}$ ' were the model constants and ' $\beta_{\mathrm{s}}$ ' was known to be Sips exponent. This model explained that the isotherm was compatible to Freundlich model at low adsorbate concentrations, the compatibility shifted to Langmuir at high concentrations. The equation defines Langmuir model at $\beta_{\mathrm{s}}=1$ (Foo and Hameed, 2010; Baybaş and Ulusoy, 2011).

$$
Q=\frac{K_{s} C_{e}^{\beta_{s}}}{1+a_{s} C_{e}^{\beta_{s}}}
$$

These models were commonly considered in obtaining adsorption characteristics of any sorbents and of sorption processes. The obtained parameters were used as references for comparison of e.g. adsorption dependence on sorbents and/or processes. According to Wang et al. (2012), Langmuir model should be further evaluated by taking into account of the contribution natively adsorbed exchangeable phosphorous (NAP) to adsorption process ( $E q$. 5, where $\mathrm{C}^{0}{ }_{\mathrm{e}}$ denotes equilibrium concentration of exchangeable phosphorous i.e. the concentration in desorption equilibrium by fresh water). $\mathrm{EPC}_{0}$ (zero phosphorous concentration) as the threshold concentration referring the release of phosphorous from the reservoir sediment back into the water when ' $\mathrm{EPC}_{0}>$ Soluble Reactive Phosphorous (SRP)' can be foreseen after NAP by Equation 6.

$$
N A P=\frac{X_{L} K_{L} C_{e}^{0}}{1+K_{L} C_{e}^{0}}+C_{e}^{0} \frac{V}{m}
$$




$$
E P C_{0}=\frac{N A P}{K_{L}\left(X_{L}-N A P\right)}
$$

The adsorbed amounts calculated by Equation 1 with reference to the phosphorous contents of solutions taken by time intervals were evaluated in view of the compatibility of adsorption to pseudo-first and -second order models (Eqs. 7 and 8) where ' $\mathrm{Q}_{\mathrm{t}}$ ' $\left(\mathrm{mg} \mathrm{kg}^{-1}\right)$ defines the adsorbed amounts at time ' $\mathrm{t}(\mathrm{h})$ ', ' $\mathrm{Q}_{1}$ and $\mathrm{Q}_{2}$ ' are the theoretical adsorptions obtained from the compatibilities. The adsorption rate constants are referred by ' $\mathrm{k}_{1}\left(\mathrm{~h}^{-1}\right)$ and $\mathrm{k}_{2}\left(\mathrm{mg}^{-1} \cdot \mathrm{kg} \mathrm{h}^{-1}\right)$ ' for first and second order kinetics (Ho and McKay, 1999).

$$
\begin{aligned}
& Q_{t}=Q_{1}\left(1-e^{-k_{1} t}\right) \\
& \frac{t}{Q_{t}}=\frac{1}{k_{2} Q_{2}^{2}}+\frac{t}{Q_{2}}
\end{aligned}
$$

Time required reducing initial phosphorous concentration to its half i.e. the time passed reaching half of the maximum adsorption ' $\mathrm{t} 1 / 2 \mathrm{~h}$ ( $)$ ' and the initial adsorption rate ' $\mathrm{H}$ (mg. $\left.\mathrm{kg}^{-1} \cdot \mathrm{st}^{-1}\right)$ ' are given by Equations 9-12 for pseudo first and second-order kinetics models.

$$
\begin{gathered}
t_{1 / 2}=0.693 / k_{1} \\
H_{1}=k_{1} Q_{1} \\
t_{1 / 2}=1 / k_{2} Q_{2} \\
H_{2}=k_{2} Q_{2}^{2}
\end{gathered}
$$

Adsorption activation energy, EA $\left(\mathrm{J} \mathrm{mol}^{-1}\right)$ is calculated by Arrhenius equation (Eq. 13) rearranged for rate constants $\left(\mathrm{k}_{\mathrm{T} 1}\right.$ and $\left.\mathrm{K}_{\mathrm{T} 2}\right)$ obtained for two different temperatures where ' $\mathrm{T}$ ' and ' $\mathrm{R}$ ' are temperature in Kelvin scale $(\mathrm{K})$ and ideal gas constant (8.314 $\mathrm{J} \mathrm{mol}^{-1} \mathrm{~K}^{-1}$ ) respectively (Winzor and Jackson, 2006).

$$
\ln \frac{k_{T 2}}{k_{T 1}}=-\frac{E_{a}}{R}\left(\frac{1}{T_{2}}-\frac{1}{T_{1}}\right)
$$

Further evaluation of the kinetics by Weber-Morris Model (Eq. 14; $\mathrm{k}_{\mathrm{i}}$ is the rate constant for the model) provides information for the nature of adsorption, i.e., the process most effective on adsorption and its kinetics amongst mass transfer/diffusion, adsorption by surface precipitation or electrostatic attraction between adsorbent and adsorbate, and intrapartical diffusion could be proposed.

$$
Q_{t}=k_{i} \sqrt{t}
$$

Adsorption thermodynamics is evaluated by Gibbs-Helmotz and van t'Hoff equations (Eqs. 15 and 16) for which the values ' $\mathrm{ln} \mathrm{K}_{\mathrm{T}}$ ' (distribution coefficient 
obtained from the ratio of the amount adsorbed to equilibrium concentration after the solid-solution interaction is ceased, $K_{T}=Q_{T} / C_{T}$ ) vs. ' $1 / T$ ' for the studied temperatures is firstly depicted to figure out the changes in adsorption entropy $\left(\Delta \mathrm{S}, \mathrm{J} \mathrm{mol}^{-1} \mathrm{~K}^{-1}\right)$ from the intercept and enthalpy $\left(\Delta \mathrm{H}, \mathrm{J} \mathrm{mol}^{-1}\right)$ and from the slope. Adsorption free energy $(\Delta \mathrm{G}$, $\mathrm{J} \mathrm{mol}^{-1}$ ) is then calculated.

$$
\begin{gathered}
\ln K_{T}=-\frac{\Delta H}{R} \frac{1}{T}+\frac{\Delta S}{R} \\
\Delta G=\Delta H-T \Delta S
\end{gathered}
$$

\section{Results}

\section{The experimental isotherms and adsorption parameters}

Figures 2 and 3 show the compatibility of concentration dependence of phosphorous adsorption to Langmuir and Freundlich models. Sips models is not provided in the figures to avoid chaotic view. The parameters derived from the compatibilities to all three models considered are presented in Table 1.

Table 1. The adsorption parameters for various temperatures for adsorption of phosphorous on Lake Mogan sediment collected in July and October $\left(C_{0}=0.1-10 \mathrm{mg} \mathrm{L}^{-1}\right.$,

\begin{tabular}{|c|c|c|c|c|c|c|c|c|c|c|}
\hline & \multicolumn{3}{|c|}{ Langmuir } & \multicolumn{3}{|c|}{ Freundlich } & \multicolumn{4}{|c|}{ Sips } \\
\hline & ${ }^{1} \mathbf{X}_{\mathrm{L}}$ & ${ }^{2} \mathbf{K}_{\mathrm{L}}$ & $\mathbf{R}^{2}$ & $\mathbf{a}$ & $\boldsymbol{\beta}$ & $\mathbf{R}^{2}$ & $\mathbf{K}_{\mathrm{s}}$ & $\mathbf{a}_{\mathrm{s}}$ & $\boldsymbol{\beta}_{\mathrm{s}}$ & $\mathbf{R}^{2}$ \\
\hline July-277K & 1001 & 0.47 & 0.975 & 300 & 0.65 & 0.972 & 431 & 0.37 & 0.92 & 0.975 \\
\hline July-289K & 655 & 2.87 & 0.947 & 434 & 0.44 & 0.936 & 1109 & 1.35 & 0.76 & 0.952 \\
\hline July-295K & 711 & 0.46 & 0.983 & 217 & 0.56 & 0.985 & 259 & 0.17 & 0.68 & 0.986 \\
\hline July-300K & 907 & 0.21 & 0.954 & 167 & 0.66 & 0.971 & 85 & -0.43 & 0.34 & 0.981 \\
\hline$*$ Mean \pm SEM & $819 \pm 81$ & & & & & & & & & \\
\hline Oct-277K & 421 & 1.92 & 0.955 & 229 & 0.4 & 0.942 & 488 & 0.88 & 0.7 & 0.967 \\
\hline Oct-289K & 654 & 1.17 & 0.942 & 308 & 0.52 & 0.962 & 316 & 0.02 & 0.53 & 0.962 \\
\hline Oct-295K & 513 & 1.71 & 0.941 & 262 & 0.47 & 0.95 & 380 & 0.35 & 0.6 & 0.952 \\
\hline Oct- $300 \mathrm{~K}$ & 531 & 0.8 & 0.944 & 223 & 0.43 & 0.914 & 486 & 1.05 & 1.35 & 0.947 \\
\hline${ }^{*}$ Mean \pm SEM & $530 \pm 48$ & & & & & & & & & \\
\hline
\end{tabular}
$\mathrm{m} / \mathrm{V}=0.25 \mathrm{~g} / 20 \mathrm{~mL}$ )

Although the results of compatibility of experimental isotherms to all adsorption models considered were significant with coefficient of variations of $R^{2} \geq 0.936$ $(\mathrm{p}<0.05)$ the best fits were obtained for the Sips (Table 1). This could be attributed to the theoretical considerations of the model which is combination of both Langmuir and Freundlich models. The mean of maximum adsorption values obtained for the defined temperatures for samples collected in July was $819 \pm 81 \mathrm{mg} \mathrm{kg}^{-1}$ as it is significantly different $(\mathrm{p}<0.05)$ from those collected in October $\left(530 \pm 48 \mathrm{mg} \mathrm{kg}^{-1}\right)$. This should be attributed to the heat activation of the sediment as depending on the weathering, i.e., the sediment of Mogan is subjected to heat a prolonged period of time in summer. In fact 
the mean of temperatures reached were $25.25 \pm 0.03{ }^{\circ} \mathrm{C}$ in July and $10.23 \pm 0.05{ }^{\circ} \mathrm{C}$ in October. The significance of the adsorption mean values also imply that the studying of adsorption at changing temperatures is not much effect on adsorption capacities because of the interaction time of solution and sediment in batch experiments is not enough $(24 \mathrm{~h})$ to change temperature associated sediment feature. The experiments to recover the phosphorous adsorbed on the sediments samples by distilled water proved that the adsorption is not reversible so that the corresponding amounts with phosphorous concentrations in recovery solutions were $<1 \%$ of the adsorbed quantities.

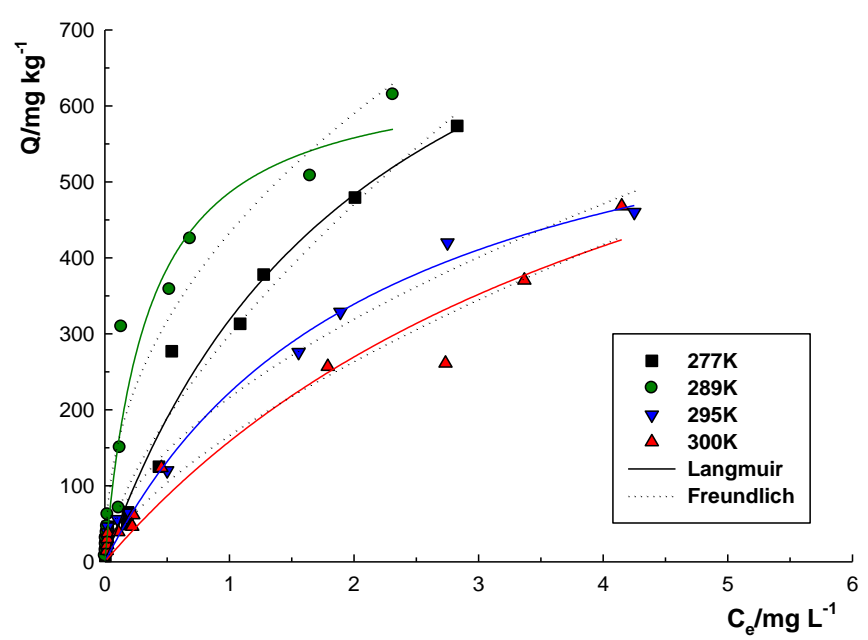

Figure 2. The experimental isotherms for various temperatures obtained for adsorption of phosphorous on sediments sampled in July and its compatibility to Langmuir and Freundlich models. [For each experimental data, $Q$ is the adsorbed amount of phosphorous on to sediment sample calculated from the phosphorous concentrations at initial $\left(C_{0}\right)$ and equilibrium $\left(C_{e}\right)$ by using Equation 1, please see section "Data Evaluation” for details] $\left(C_{0}=0.1-10 \mathrm{mg} \mathrm{L}^{-1}\right.$, $\mathrm{m} / \mathrm{V}=0.25 \mathrm{~g} / 20 \mathrm{~mL}$ )

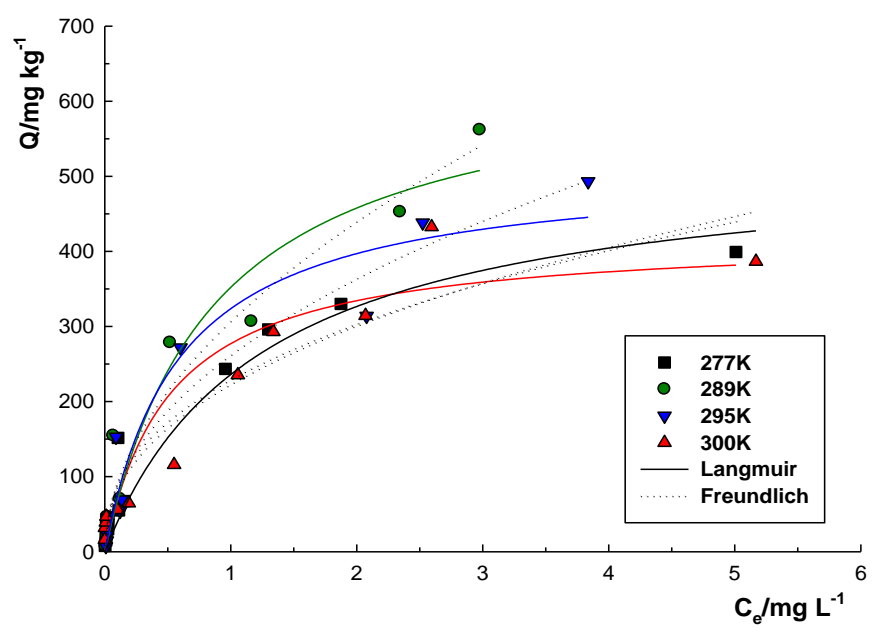

Figure 3. The experimental isotherms for various temperatures obtained for adsorption of phosphorous on sediments sampled in October and its compatibility to Langmuir and

Freundlich models. [For each experimental data, $Q$ is the adsorbed amount of phosphorous on to sediment sample calculated from the phosphorous concentrations at initial $\left(C_{0}\right)$ and equilibrium $\left(C_{e}\right)$ by using Equation 1, please see section "Data evaluation" for details]

$$
\left(C_{0}=0.1-10 \mathrm{mg} \mathrm{L}, \mathrm{m} / \mathrm{V}=0.25 \mathrm{~g} / 20 \mathrm{~mL}\right)
$$


Table 2 provides results relevant to $\mathrm{NAP}$ and $\mathrm{EPC}_{0}$. The comparison of the magnitudes of NAP with that of $X_{L}$ values predicated that contribution of NAP to adsorption process is not considerable for any of the studied conditions. The values of $\mathrm{EPC}_{0}$ were in the range of $0.004-0.012 \mathrm{mg} \mathrm{L}^{-1}$ for the sediments sampled in both seasons which is less than the values of SRP $0.018 \pm 0.009$ and $0.039 \pm 0.003 \mathrm{mg} \mathrm{L}^{-1}$ for July and October sediments respectively.

Table 2. NAP (natively adsorbed exchangeable phosphorous) and zero phosphorous concentration $\left(E P C_{0}\right.$; the threshold concentration referring the release of phosphorous from the reservoir sediment back into the water) values for Lake Mogan sediment calculated by using Langmuir parameters $\left(X_{L}\right.$ and $\left.K_{L}\right)$ and the equilibrium concentrations $\left(\mathrm{Ce}^{0}\right)$ for various temperatures

\begin{tabular}{|c|c|c|c|c|c|c|}
\hline & ${ }^{1} \mathbf{X}_{\mathrm{L}}$ & ${ }^{2} \mathbf{K}_{\mathbf{L}}$ & ${ }^{3} \mathrm{C}_{\mathrm{e}}{ }^{0} \times 10^{3}$ & ${ }^{1} \mathbf{N A P}$ & ${ }^{3} \mathrm{EPC}_{0} \times 10^{3}$ & ${ }^{4}\left(\mathrm{NAP} / \mathrm{EPC}_{0}\right)$ \\
\hline July-277K & 1001 & 0.47 & 3.8 & 2.1 & 4.4 & 477 \\
\hline July-289K & 655 & 2.87 & 3.8 & 7.4 & 4 & 1850 \\
\hline July-295K & 513 & 1.71 & 4.2 & 1.9 & 5.8 & 328 \\
\hline July-300K & 907 & 0.21 & 8.9 & 2.4 & 12.6 & 190 \\
\hline Oct-277K & 421 & 1.92 & 3.7 & 3.2 & 4.0 & 800 \\
\hline Oct-289K & 654 & 1.17 & 4.1 & 3.4 & 4.5 & 755 \\
\hline Oct-295K & 711 & 0.46 & 4.6 & 4 & 4.6 & 870 \\
\hline Oct-300K & 531 & 0.8 & 9.6 & 4.8 & 11.4 & 421 \\
\hline
\end{tabular}

${ }^{1} \mathrm{mg} \mathrm{kg}^{-1}$

${ }^{2} \mathrm{~L} \mathrm{mg}^{-1}$

${ }^{3} \mathrm{mg} \mathrm{L}^{-1}$

${ }^{4} \mathrm{~L} \mathrm{~kg}^{-1}$

\section{Adsorption kinetics}

Time dependence of phosphorous adsorption on sediment samples were investigated to evaluate the adsorption with reference to pseudo first and second order models of the kinetics for sediments sampled in July and October for two different temperatures. The compatibility of experimental data to the models from which the parameters were obtained are presented in Figure 4, and Table 3.
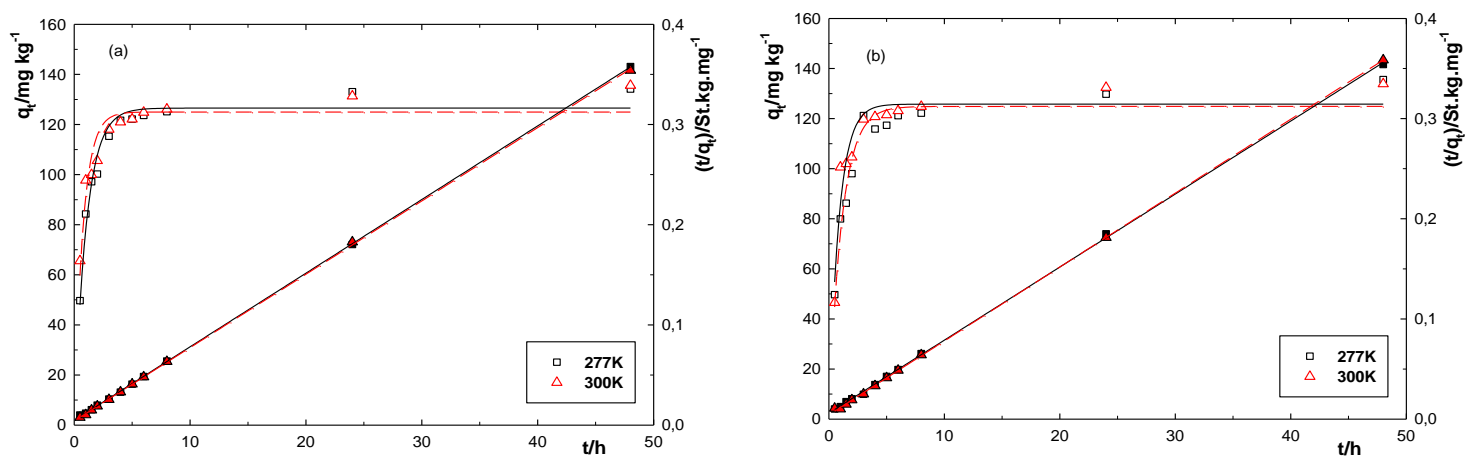

Figure 4. The compatibility of experimental data for July (a) and October samples (b) at 277 and $300 \mathrm{~K}$ to pseudo-first ( $i$ vs. qt) and second order ( $t$ vs. $t / q t$ ) kinetic models;' ' $t$ ' and 'qt 'refer the time elapsed after the solid-solution contact as hour and adsorbed amounts calculated for time ' $t$ ' as mol $\mathrm{kg}-1(\mathrm{CO}=2 \mathrm{mg} \mathrm{L}-1, \mathrm{~m} / \mathrm{V}=0.25 \mathrm{~g} / 20 \mathrm{~mL})$ 
Table 3. Kinetic parameters derived from the compatibility of time dependence of phosphorous adsorption to pseudo first and second order models

\begin{tabular}{|c|c|c|c|c|c|c|c|c|c|}
\hline \multirow{3}{*}{ July-277K } & \multicolumn{6}{|c|}{ Pseudo first order } & \multicolumn{3}{|c|}{ Pseudo second order } \\
\hline & \multicolumn{2}{|c|}{${ }^{1} Q_{\text {exp }}(6-48)^{2}$} & \multirow{2}{*}{$\begin{array}{c}{ }^{\mathbf{1}} \mathbf{Q}_{1} \\
0.95\end{array}$} & \multirow{2}{*}{$\begin{array}{c}{ }^{3} \mathbf{k}_{\mathbf{1}} \\
0.962\end{array}$} & \multirow{2}{*}{$\frac{\mathbf{R}^{\mathbf{2}}}{0.7(89)^{6}}$} & \multirow{2}{*}{$\frac{{ }^{4} \mathbf{t}_{1 / 2}}{136}$} & \multirow{2}{*}{$\begin{array}{c}{ }^{1} \mathbf{Q}_{\mathbf{2}} \\
11.7\end{array}$} & \multirow{2}{*}{$\begin{array}{c}{ }^{\mathbf{5}_{\mathbf{2}} \mathbf{x} 10^{\mathbf{3}} \mathbf{R}^{\mathbf{2}}} \\
0.999\end{array}$} & \multirow{2}{*}{$\frac{{ }^{\mathbf{4}_{\mathbf{t}_{\mathbf{1} / \mathbf{2}}}}}{0.6(216)^{6}}$} \\
\hline & $124-134$ & 127 & & & & & & & \\
\hline July-300K & $125-136$ & 125 & 1.3 & 0.894 & $0.5(63)$ & 137 & 12.9 & 0.999 & $0.6(242)$ \\
\hline Oct-277K & $121-136$ & 125 & 0.89 & 0.943 & $0.8(111)$ & 137 & 9.00 & 0.999 & $0.8(169)^{6}$ \\
\hline Oct-300K & $123-133$ & 126 & 1.14 & 0.914 & $0.6(76)$ & 135 & 13.00 & 0.999 & $0.6(237)$ \\
\hline $\begin{array}{l}{ }^{1} \mathrm{mg} \mathrm{kg}^{-1} \\
{ }^{2} \text { The adsorb } \\
{ }^{3} \mathrm{~h}^{-1} \\
{ }^{4} \mathrm{~h}^{-1} \\
{ }^{5} \mathrm{mg}^{-1} \cdot \mathrm{kg}^{-\mathrm{h}^{-1}} \\
{ }^{6} \text { Initial adss }\end{array}$ & i. & & & 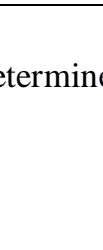 & & & & & \\
\hline
\end{tabular}

As seen from the table that the phosphorous adsorption kinetics obeyed more significantly to second order model $\left(\mathrm{R}^{2} \geq 0.999\right)$ than that to the first order model. This was also consistent with closeness of the values for $\mathrm{Q}_{2}$ (the adsorbed amounts found from second order model) and $\mathrm{Q}_{\exp }$ (the adsorbed amounts after experimental equilibrium). Adsorption rate constants proved that the increasing temperatures increase the adsorption rates $\mathrm{k}_{2}(300 \mathrm{~K})>\mathrm{k}_{2}(277 \mathrm{~K})$, although this was not significant for $\mathrm{P}$ adsorption on the Mogan Sediments at the studied conditions. From the comparison of $\mathrm{Q}_{\max }$ and $\mathrm{Q}_{2}$ values, it was obvious that $\mathrm{P}$ adsorption completed in a few hours after adsorbent-adsorbate contact. In fact that the values of $\mathrm{t}_{1 / 2}$ (time elapsed up to half of the completion of adsorption) showed that half lives were about $0.6-0.8 \mathrm{~h}$ with high initial adsorption rates ranging between $169 \mathrm{mg} \mathrm{kg}^{-1} \mathrm{~h}^{-1}$ and $242 \mathrm{mg} \mathrm{kg}^{-1} \mathrm{~h}^{-1}$. Similar trends were also seen from the parameters derived from first order model. The adsorption activation energy was calculated and evaluated under thermodynamics section because of energetically relevance of the subjects.

The adsorption kinetics of $\mathrm{P}$ was further evaluated with reference to Weber-Morris model to figure out the physicochemical nature of adsorption for which the graph of Q vs. $\mathrm{t}^{0.5}$ was obtained by using all the data obtained from the adsorption kinetics to signify the figure's pattern which could be considered with two parts (Fig. 5). The profile of graph was typical for adsorption of species to an adsorbent with chemical feature; otherwise, the pattern is with a straight linearity passing through the origin for adsorptions with physical nature.

\section{Adsorption thermodynamics}

Temperature dependence of P adsorption on Lake Mogan sediments studied for 289, 295 and $300 \mathrm{~K}$ for both sediment samples of the July and October. The obtained data were evaluated with reference to Gibbs-Helmotz and van t'Hoff equations for which the linearity of ' ln K vs. 1/T' depiction was considered (Fig. 6). The values acquired from slop and intercept of the linear relation $\left(\mathrm{R}^{2} \geq 0.974\right)$ were used to calculate Gibbs free enthalpy of the adsorption. The results were exhibited in Table 4. Because of its energetical relevance, the activation energy of the adsorption derived from the kinetics studies was also represented in the table. 


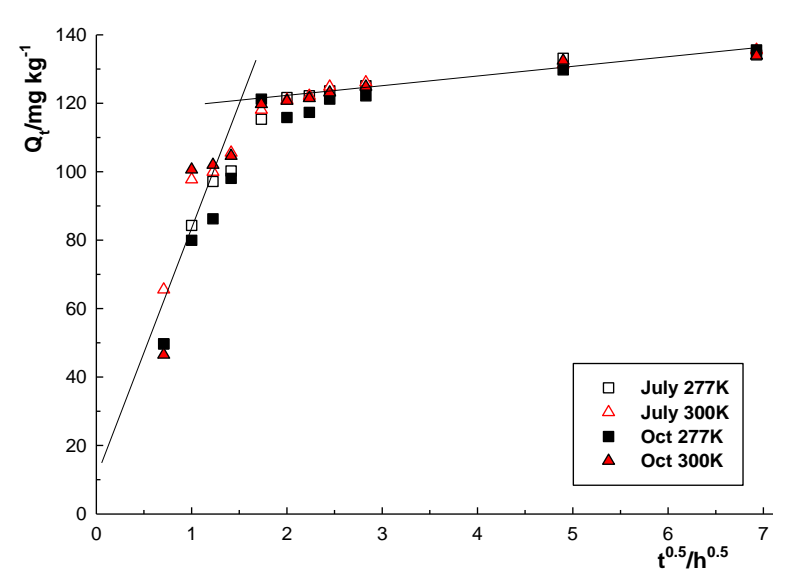

Figure 5. The compatibility of experimentally obtained data from the kinetics of $P$ adsorption to Weber-Morris Model

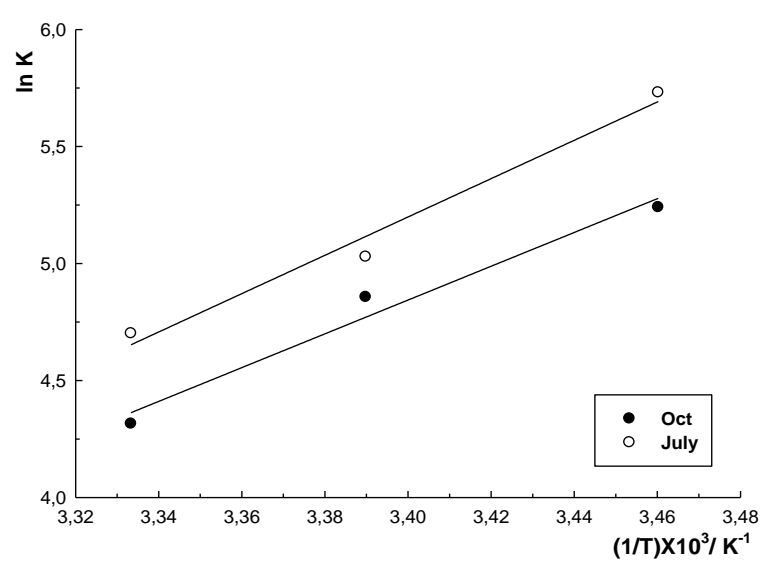

Figure 6. Compatibility of the temperature dependence of $P$ adsorption to linearity $\left(C_{0}=10 \mathrm{mg}\right.$ $L^{-1}, m / V=0.25 \mathrm{~g} / 20 \mathrm{~mL}$ )

Table 4. Thermodynamic parameters for adsorption of $P$ to sediment samples

\begin{tabular}{|c|c|c|c|c|c|}
\hline & $\Delta H\left(\mathrm{~kJ} \mathrm{~mol}^{-1}\right)$ & $\Delta \mathrm{S} \mathrm{J} \mathrm{mol}{ }^{-1} \mathrm{~K}^{-1}$ & $\Delta \mathbf{G}_{298 \mathrm{~K}}\left(\mathrm{~kJ} \mathrm{~mol}^{-\mathbf{1}}\right)$ & $\mathbf{R}^{2}$ & $E_{a}\left(k \mathrm{~mol}^{-1}\right)$ \\
\hline July & -68.1 & -188 & -12.1 & 0.979 & 2.9 \\
\hline Oct & -60 & -164 & -11.1 & 0.974 & 11 \\
\hline
\end{tabular}

$\Delta \mathrm{H}, \Delta \mathrm{S}$ and $\Delta \mathrm{G}$ are of the state functions and represent the energetically changing overall adsorption process which here refers to the changes in not only $\mathrm{P}$ adsorption alone but also in the contributions made by all other interactions in adsorption medium (such as $\mathrm{P}$ hydrolysis/hydration of $\mathrm{P}$ ions, water and sediment contents interaction, and many others) to the process. The results demonstrated that overall adsorption process was exothermic $(\Delta H<0)$ with decreasing entropy $(\Delta S<0)$, and spontaneous $(\Delta \mathrm{G}<0)$ under enthalpy influence $(\Delta \mathrm{H}-\Delta \mathrm{S}<0)$. The energy released after adsorption is not big enough to form a covalent bonding $\left(\Delta \mathrm{H} \approx 200 \mathrm{~kJ} \mathrm{~mol}^{-1}\right)$ but it is sufficient to identify the presence of highly strong interactions between $\mathrm{P}$ species and sediment surface via electrostatic attractions This should also further evidence for the occurrence of 
adsorption is via surface precipitation. Activation energy, the threshold to be overcome for the adsorption did not have considerable impact opposing to the adsorption at studied temperatures. However the value of Ea for July samples significantly lower than that for October samples because of the heat activation of the sediment during summer season as discussed above, as concordant with the results of $\Delta \mathrm{H}$ found for the same seasonal sediments.

The phosphorus desorption for all the sediment samples under different temperature applications in both months were all calculated at less than $1 \%$, these values were not taken into consideration.

\section{Discussion}

Langmuir and Freundlich's equations were used in order to estimate the phosphate adsorption in the sediment of Lake Mogan. The equilibrium phosphate concentration was determined using the mentioned kinetic models, and the rate of the chemical reaction during the adsorption process was measured. During the research, the effects of four different temperatures $(277 \mathrm{~K}, 289 \mathrm{~K}, 295 \mathrm{~K}, 300 \mathrm{~K})$ reflecting the natural conditions of phosphate sorption in the sediment of Lake Mogan were taken into account, and thus, measurements were taken during the months of October and July.

As reported by Huang et al. (2011), since shallow lakes are often isothermal, their sediments are sensitive to temperature changes, and the initial rates of sediment phosphorus adsorption are in direct proportion to the temperature. The constant values for the phosphorus adsorption rate in Lake Mogan for October and July were estimated at between 169-277 mg kg-1 $\mathrm{h}^{-1}$ and 216-242 $\mathrm{mg} \mathrm{kg}^{-1} \mathrm{~h}^{-1}$ at temperatures of $(\mathrm{k}) 277 \mathrm{~K}$ and $300 \mathrm{~K}$, respectively. The fact that these values for the lake sediment increased in direct proportion to the increase in temperature was in accordance with the abovementioned research findings.

According to Wang et al. (2009) in a study on Three-Gorges Reservoir (China), the phosphate adsorption rate from the sediment reached its peak within six hours, and the maximum phosphate adsorption amount was $0.15-0.402 \mathrm{mgP} \mathrm{g}^{-1}$. The kinetic characteristic of P-sorption in sediment is described by the Elovich model in sediment of Dongting Lake (Zhu and Yang, 2018). The rapid stage of P adsorption occurs within $60 \mathrm{~min}$, and then, slow P sorption appears between 60 and $240 \mathrm{~min}$. The P-sorption amount of sediment changes smaller after $240 \mathrm{~min}$. The phosphate adsorption rate in Lake Mogan was at 90\% within six hours that takes longer than Zhu and Yang (2018) and the maximum phosphate adsorption amount was estimated at $421-1001 \mathrm{mgP} \mathrm{kg}^{-1}$. While the phosphate adsorption rate in this study resembles that reported in Wang et al. (2009), the extremely high maximum phosphate adsorption amounts in the ThreeGorges Reservoir were found to be lower (137.79-1975.50 mg kg-1) in another study undertaken in the same reservoir by Zhang et al. (2012). In that study, the phosphate sorption activity in the sediment was determined to be $47.341-230.88 \mathrm{~L} \mathrm{~kg}^{-1}$ (Zhang et al., 2012). Lake Mogan's sediment phosphate sorption activity (0.21-1.92 $\mathrm{L} \mathrm{mg}^{-1}$ ) is higher than the findings of the above study.

Lai and Lam (2008) revealed sediment phosphate adsorption/release and the factors affecting this mechanism in Hong Kong's eutrophic Mai Po Marshes. The study's estimated $\mathrm{EPC}_{0}$ values were lower than the overlying water's SRP concentrations, and the sediment phosphate release level under aerobic conditions was found to be, on average, $9.4 \mathrm{mg} \mathrm{m}^{-2} \mathrm{day}^{-1}$. The $\mathrm{EPC}_{0}$ values in Lake Mogan were similar to the findings 
of Lai and Lam (2008) in that they were found to be lower than the overlying water SRP concentrations. When the $\mathrm{EPC}_{0}$ and the overlying water SRP concentrations were examined in the present study, it was suggested that internal phosphate loading from the sediment has a lower effect on the current nutrient level of the lake than the external phosphate load.

In Cry et al.'s (2009) study of oligomesotrophic Opeongo Lake (Canada), when the highest estimated $\mathrm{EPC}_{0}$ values in the sediment $\left(5 \mu \mathrm{gP} \mathrm{L}^{-1}\right)$ and the unmeasurable level of SRP values in the overlying water were considered, it was dertermined that there was a phosphate reserve in the sediment. In Nansi Lake (China), kinetic and adsorption/desorption isotherms were detected in the sediment and the equilibrium phosphate concentration and phosphate release potential were estimated, and it was determined that $\mathrm{EPC}_{0}<\mathrm{SRP}$ (Li et al., 2012). The fact that the estimated $\mathrm{EPC}_{0}$ values in Lake Mogan were found to be lower than the SRP concentrations measured in the overlying water shows agreement with the reports of the above researchers.

In a study examining the details of phosphate adsorption at the sediment-water interface in Fushi Reservoir (China), sorption isothermic experiments were defined using the Langmuir and Freundlich models. When comparing the $\mathrm{EPC}_{0}$ values with the overlying water SRP values, it was emphasized that the higher $\mathrm{EPC}_{0}$ values facilitated phosphate release from the sediment, and that the sediment played a role as a phosphate source (Wang et al., 2012). Shoja et al. (2017), in their study of Ekbatan Reservoir (Iran), found that the $\mathrm{EPC}_{0}$ value was much higher than the SRP concentration and that, despite the high adsorption capacity of the sediment, phosphate release from the sediment could occur. The fact that the estimated $\mathrm{EPC}_{0}$ values in Lake Mogan are lower than the SRP concentrations found in the overlying water, unlike the findings of Wang et al. (2012) and Shoja et al. (2017), points to phosphorus adsorption in the sediment.

According to Fang et al. (2017) the role of particle morphology of clay minerals in P adsorption were studied. They revealed that Sips model can provide a better prediction than the Langmuir model, especially for kaolinite and hematite minerals and performs improvements as compared to the Langmuir model. This better performance could be attributed to the consideration of particle morphology reflected in the heterogeneity coefficient $\gamma$ and adsorption capacity $Q_{m}$. The fact that the correlation coefficients calculated for the Sips model in Lake Mogan were greater than the values found for the Langmuir and Freundlich models shows the heterogenous behavior of the low phosphorus concentrations on the sediment surface in line with the researchers below. This finding supports the case for high adsorption levels in the lake. Moreover, during the research period, the low phosphorus concentration in the overlying water and the phosphorus fractions undergoing irregular changes in the sediment (Topçu and Pulatsu, 2017) concur with the finding that the sediment's phosphorus adsorption mechanism behaves heterogeneously.

Wang and $\mathrm{Li}$ (2010) studied the phosphorus adsorption and desorption mechanism in sediment samples obtained from six different sources in America (canal, ocean, coastal, river, marsh and lake). The estimated NAP and $\mathrm{EPC}_{0}$ values in the canal and lake sediments were found to be higher than in the other sources. The phosphorus adsorption values in the sediment were calculated in order as Coastal $>$ Marsh>Ocean. In the scope of the research it was reported that the desorption potential of the coastal and marsh sediment samples was extremely low. The fact that the phosphorus desorption value in Lake Mogan, one of Turkey's important wetlands, was found to be lower than $1 \%$ supports the high phosphorus adsorption value $\left(907 \mathrm{mg} \mathrm{kg}^{-1}\right)$ and the low NAP (4.8- 
$\left.11.7 \mathrm{mg} \mathrm{kg}{ }^{-1}\right)$ and $\operatorname{EPC}_{0}\left(5.5 \times 10^{-3}-46.6 \times 10^{-3} \mathrm{mg} \mathrm{L}^{-1}\right)$ values determined for the sediment. Our findings concur with Wang and Li's (2010) report stating that high values for adsorption in the sediment are effective at keeping desorption at low levels.

Tang et al. (2014) reported that the values for the energy released through phosphorus adsorption (Ea) are in inverse proportion to the calculated phosphorus adsorption in the sediment. The fact that the phosphorus adsorption energy (Ea) values reported in Lake Mogan were lower for the samples taken in July than those taken in October supports the finding that phosphate adsorption values were calculated to be at a maximum in July. Prevalence of $\Delta \mathrm{H}$ with a high magnitude is generally evidence for the high adsorption energy affinity of $\mathrm{P}$ to the sediment. The results of the thermodynamics experiments demonstrated that overall, the adsorption process was exothermic $(\Delta H<0)$ with decreasing entropy $(\Delta S<0)$, and spontaneous $(\Delta G<0)$ under the influence of enthalphy $(\Delta \mathrm{H}-\Delta \mathrm{S}<0)$. The high-magnitude values of $\Delta \mathrm{H}$ signal strong interactions between phosphorus species and the sediment surface via electrostatic attraction. Adsorption activation energy did not have a significant impact on adsorption resistance at the temperatures in this study.

Experimentally obtained isotherms for phosphorus adsorption onto Lake Mogan sediments were well compatible to all three adsorption models considered $\left(R^{2} \geq 0.936\right.$; $\mathrm{p}<0.05$ ). Based on Langmuir the Model, the mean of maximum adsorption capacity obtained for July samples was significantly higher than that obtained for October samples $(p<0.05)$. This was attributed to heat activation of July samples due to the exposure of sunlight. The adsorbed phosphorous was not recoverable by distilled water. The comparison of $\mathrm{EPC}_{0}$ and SRP values signified that the soluble phosphorous do not release from the sediment into the lake water.

The adsorption kinetics comply with the second order model with a high significance $\left(\mathrm{R}^{2} \geq 0.999\right)$. Phosphorous adsorption completed in a few hours after adsorbentadsorbate contact with a period of 0.6-0.8 $\mathrm{h}$ with high initial adsorption rates (169$242 \mathrm{mg} \mathrm{kg}^{-1} \mathrm{~h}^{-1}$ ). The overall adsorption process was surface precipitation with a high mass transfer to the boundary layer after evaluation of the kinetics with reference to Weber-Morris model.

\section{Conclusions}

The sediment's equilibrium phosphate concentration value is used in estimating the phosphorus concentration in the overlying water, which may negatively affect the nutrient value of a lake. With this study, it has been scientifically proven through laboratory research that there may be a risk of phosphorus release from the sediment when the overlying water SRP concentration for October of $0.008 \mathrm{mg} \mathrm{L}^{-1}$ falls below the July value of $0.046 \mathrm{mg} \mathrm{L}^{-1}$. Accordingly, considering the overlying water SRP values reported above for Lake Mogan, monitoring them especially in the months of October and July will prove to be decisive in predicting the internal phosphorus load of the lake.

Acknowledgements. This research is supported by Turkish Scientific and Technological Research Council TUBITAK Project No. TOVAG :115Y375).

Conflicts of interest. The authors declare that they have no conflicts of interest. 


\section{REFERENCES}

[1] APHA (2005): Standard Methods for the Examination of Water and Waste Water. $21^{\text {st }}$ edn. - American Public Health Association, Washington, DC.

[2] Baybaş, D., Ulusoy, U. (2011): Polyacrylamide-clinoptilolite/Y-zeolite composites: Characterization and adsorptive features for terbium. - Journal of Hazardous Materials 187: 241-249.

[3] Boşgelmez, A., Boşgelmez, İ. İ., Savcı, A. E., Aldemir, A., Gürpınar, E., Mutlu, B., Topaloğlu, S., Ege M, Çiçek N (2005): Ankara-Gölbaşı and Centaurea tchihatcheffii. Centaurea tchihatcheffii Ankara-Gölbaşı Sevgi Çiçeği, Ankara, pp. 131-178.

[4] Cry, H., McCabe, S. K., Nurnberg, G. K. (2009): Phosphorus sorption experiments and the potential for internal phosphorus loading in littoral areas of a stratified lake. - Water Research 43: 1654-1666.

[5] Fang, H., Cui, Z., He, G., Huang, L., Chen, M. (2017): Phosphorus adsorption onto clay minerals and iron oxide with consideration of heterogeneous particle morphology. Science of the Total Environment 605-606: 357-367.

[6] Foo, K. Y., Hameed, B. H. (2010): Insights into the modeling of adsorption isotherm systems. - Chemical Engineering Journal 156: 2-10.

[7] Ho, Y. S., McKay, G. (1999): Pseudo-second order model for sorption processes. Process Biochemistry 34: 451-465.

[8] Huang, L., Fu, L., Jin, C., Gielen, G., Lin, X., Wang, H., Zhang, Y. (2011): Effect of temperature on phosphorus sorption to sediments from shallow eutrophic lakes. Ecological Engineering 37: 1515-1522.

[9] Jin, X., He, Y., Kirumba, G., Hassan, Y., Li, J. (2013): Phosphorus frations and phosphate sorption-release characteristics of the sediment in the Yangtze River estuary reservoir. - Ecological Engineering 55: 62-66.

[10] Lai, D. Y. F., Lam, K. C. (2008): Phosphorus sorption by sediments in a subtropical constructed wetland receiving stormwater runoff. - Ecological Engineering 35: 735-743.

[11] Li, Z., Yue, Q., Gao, B., Wang, Y., Liu, Q. (2012): Phosphorus release potential and pollution characteristics of sediment in downstream Nansi Lake, China. - Front. Environ. Sci. Engin. 6(2): 162-170.

[12] Palmer-Felgate, E. J., Bowes, M. J., Stratford, C., Neal, C., MacKenzie, S. (2011): Phosphorus release from sediments in a treatment wetland: contrast between DET and $\mathrm{EPC}_{\mathrm{o}}$ methodologies. - Ecological Engineering 37: 826-832.

[13] Pulatsü, S., Topcu, A. (2009): Seasonal and vertical distributions of porewater phosphorus and iron concentrations in a macrophyte-dominated eutrophic lake. - Journal of Environmental Biology 30(5): 801-806.

[14] Pulatsü, S., Topçu, A., Kırkağaç, M., Köksal, G. (2008): Sediment phosphorus characteristics in the clearwater state of Lake Mogan, Turkey. - Lakes and Reservoirs: Research and Management 13: 197-205.

[15] Shoja, H., Rahimi, G., Fallah, M., Ebrahimi, E. (2017): Investigation of phosphorus fractions and isotherm equation on the lake sediments in Ekbatan Dam (Iran). Environmental Earth Sciences 76: 235. DOI 10.1007/s12665-017-6548-2.

[16] Tang, X., Wu, M., Dai, X., Chai, P. (2014): Phosphorus storage dynamics and adsorption characteristics for sediment from a drinking water source reservoir and its relation with sediment compositions. - Ecological Engineering 64: 276-284.

[17] Topçu, A., Pulatsü, S. (2008). Phosphorus fractions in sediment profiles of the eutrophic Lake Mogan, Turkey. - Fresenius Environmental Bulletin 17(2): 164-172.

[18] Topçu, A., Pulatsü, S. (2017): Evaluation of some management strategies in eutrophic Mogan Lake, Turkey: Phosphorus mobility in the sediment-water interface. - Applied Ecology and Environmental Research 15(4): 705-717. DOI: http://dx.doi.org/10.15666/aeer/ 1504_705717. 
[19] Wang, C., Boithias, L., Ning, Z., Han, Y., Sauvage, S., Perez, J. M. S., Kuramochi, K., Hatano, R. (2017): Comparison of Langmuir and Freundlich adsorption equations within the SWAT-K model for assessing potassium environmental losses at basin scale. Agricultural Water Management 180(B): 205-211.

[20] Wang, Q., Li, Y. (2010): Phosphorus adsorption and desorption behavior on sediments of different origins. - J. Soils Sediments 10: 1159-1173.

[21] Wang, X., Zhang, L., Zhang, H., Wu, X., Mei, D. (2012): Phosphorus adsorption characteristics at the sediment-water interface and relationship with sediment properties in Fushi Reservoir, China. - Environ. Earth Science 67: 15-22.

[22] Wang, Y., Shen, Z., Niu, J., Liu, R. (2009): Adsorption of phosphorus on sediments from the Three-Gorges Reservoir (China) and the relation with sediment compositions. Journal of Hazardous Materials 162: 92-98.

[23] Winzor, D. J., Jackson, C. M. (2006): Interpretation of the temperature dependence of equilibrium and rate constants. - J. Mol. Recognit. 19: 389-407.

[24] Zhang, B., Fang, F., Guo, J., Chen, Y., Li, Z., Guo, S. (2012): Phosphorus fractions and phosphate sorption-release characteristics relevant to the soil composition of water-levelfluctuating zone of Three Gorges Reservoir. - Ecological Engineering 40: 153-159.

[25] Zhhijian, L., Yue, Q., Gao, B., Wang, Y., Liu, Q. (2012): Phosphorus release potential and pollution characteristics of sediment in downstream Nanski Lake, China. - Front. Environ. Sci. Engin. 6(2): 162-170.

[26] Zhu, G., Yang, Y. (2018): Variation laws and release characteristics of phosphorus on surface sediment of Dongting Lake. - Environmental Science and Pollution Research 25(13): 12342-12351. 